\title{
Pengungkapan Intellectual Capital, Reputasi Underwriter dan IPO Underpricing
}

\author{
Zulhawati \\ zulhawati.uty@gmail.com
}

UTY Yogyakarta

\begin{abstract}
This study examines the effect of Intellectual Capital Disclosure and Underwriter Reputation to IPO Underpricing the company public on Indonesia Stock Exchange 20072012. The Results of research on the observation period there was $80 \%$ of companies experiencing IPO underpricing. Underpricing phenomenon is deliberately done to get the attention of the company's stock price increases in the first day listing or may occur due to information asymmetries between issuers and underwriters among and investors who have information about the issuer's prospects. Information asymmetry can be reduced by presenting financial information and non-financial information in the prospectus, one of non- financial information to be presented is intellectual capital. Information about the underwriter's reputation is also required by investors as a measure of financial information that is relevant and reliable. The results of multiple regression statistical test indicates that intellectual capital disclosure and underwriter reputation negatively affect the level of underpricing. This suggests that the higher intellectual capital disclosure can reduce IPO underpricing, as well as a good underwriter reputation can reduce IPO underpricing.
\end{abstract}

Keywords: IPO underpricing, intellectual capital disclosure, underwriter reputation, information asymmetries

\section{Pendahuluan}

Peningkatan kebutuhan dana perusahaan dapat dipenuhi dengan memilih salah satu dari berbagai alternatif pendanaan yang dapat digunakan. Sumber pendanaan bisa berasal dari internal perusahaan maupun berasal dari external perusahaan. Sumber pendanaan yang berasal dari internal perusahaan dengan memanfaatkan laba yang tidak dibagi. Sedangkan sumber pendanaan yang berasal dari external perusahaan dapat berasal dari utang atau menerbitkan saham. Sumber pendanaan melalui penerbitan saham yang dijual kepada masyarakat umum dikenal dengan penawaran umum atau go public.

Perusahaan melakukan go public menjadi salah satu alternatif bagi perusahaan guna memperoleh dana tambahan untuk kegiatan ekspansi atau operasi perusahaan sedangkan bagi investor di pasar modal sebagai salah satu alternatif tempat berinvestasi. Tahapan dalam proses go public, sebelum diperdagangkan di pasar skunder, saham terlebih dahulu dijual di pasar primer atau pasar perdana yang biasa disebut dengan Initial Public Offering (IPO). Investor membeli saham di pasar perdana dengan harapan akan mendapatkan keuntungan yang diperoleh dari selisih harga lebih antara harga di pasar skunder dengan di pasar perdana atau initial return. Diperolehnya initial return berarti investor menerima abnormal return melalui IPO yang di lakukan perusahaan. Menurut Jogiyanto (2010:566) investor yang dapat kesempatan untuk membeli sekuritas yang undervalued ini akan dapat menikmati abnormal return yang ada hanya terjadi dengan waktu yang cepat dan tidak 
berkepanjangan. Ini berarti bahwa investor yang membeli beberapa saat setelah pengumuman IPO sudah tidak akan memperoleh abnormal return lagi, karena harga sekuritas sudah mencapai keseimbangan baru.

Pada saat perusahaan melakukan IPO yang dilaksanakan di pasar primer (primary market), tidak ada harga pasar saham sampai dimulainya penjualan di pasar sekunder. Pada saat tersebut umumnya investor memiliki informasi terbatas seperti yang diungkapkan dalam prospektus. Dengan demikian investor yang ingin menanamkan modalnya hanya memiliki informasi tentang perusahaan sebatas yang diinformasikan pada prospectus tersebut. Prospectus merupakan suatu laporan yang disyaratkan Bapepam kepada perusahaan yang ingin listing di pasar modal, yang berisikan gambaran umum perusahaan yang memuat keterangan secara lengkap dan jujur keadaan perusahaan dan prospeknya di masa mendatang serta memuat informasi-informasi yang diperlukan sehubungan dengan penawaran umum.

Salah satu masalah saat IPO adalah berapa harga yang tepat untuk selembar saham yang akan ditawarkan, dimana harga jual saat IPO ditentukan oleh emiten (perusahaan penerbit) dengan underwriter (penjamin emisi), sedangkan harga saham yang dijual pada pasar skunder ditentukan oleh mekanisme pasar, yaitu permintaan dan penawaran. Bila harga saat IPO lebih tinggi dibandingkan dengan harga yang terjadi di pasar skunder pada hari pertama, maka disebut dengan overpricing, sebaliknya bila harga saat IPO lebih rendah dibandingkan dengan harga yang terjadi di pasar skunder pada hari pertama, maka disebut dengan underpricing.

Kondisi underpricing sebenarnya merugikan perusahaan, karena secara financial perusahaan tidak mendapatkan dana secara maksimal, tapi menguntungkan bagi investor karena akan menerima initial return dari selisih harga beli di pasar primer dengan harga jual di pasar skunder. Underpricing yang terjadi di Bursa Efek Indonesia sangat tinggi; pada tahun 2007 dari 22 emiten 20 emiten mengalami underpricing, tahun 2008 dari 19 emiten 16 emiten mengalami underpricing, tahun 2009 dari 13 emiten 8 emiten mengalami underpricing, tahun 2010 dari 23 emiten 21 emiten mengalami underpricing, tahun 2011 dari 25 emiten 16 emiten mengalami underpricing, tahun 2012 dari 23 emiten 22 emiten mengalami underpricing. Dari tahun 2007 sampai tahun 2012 diketahui ada 125 emiten yang melakukan IPO ada 100 emiten mengalami underpricing.

Permasalahan penting yang dihadapi emiten pada saat melakukan penawaran saham perdana adalah penutupan besarnya harga saham perdana. Sedangkan sebagai pihak yang membutuhkan dana, emiten menginginkan harga yang tinggi. Di sisi lain, harga yang tinggi akan mempengaruhi respon calon investor untuk membeli saham yang ditawarkan. Sebaliknya, penjamin emisi berusaha untuk meminimalkan risiko yang ditanggungnya.

Tipe penjaminan yang berlaku di Indonesia adalah full commitment, dimana pihak penjamin emisi akan membeli saham yang tidak habis terjual saat penawaran perdana. Keadaan ini membuat penjamin emisi berupaya untuk meminimalkan risiko dengan melakukan negosiasi dengan emiten agar harga saham-saham tersebut tidak terlalu tinggi, bahkan cenderung underprice.

Fenomena underpricing dapat terjadi karena adanya asimetri informasi, dimana asimetri informasi dapat terjadi antara emiten dengan underwriter, maupun antar investor yang memiliki informasi tentang prospek emiten (Trisnaningsih 2005). Emiten menginginkan harga perdana yang tinggi agar memperoleh dana sebesar yang diharapkan, disisi lain underwriter berusaha meminimalkan risiko penjaminan dengan menentukan harga yang dapat diterima oleh investor. 
Pada proses penawaran perdana, emiten membutuhkan keterlibatan penjamin emisi sebagai perantara dalam penjualan saham dengan investor. Tinggi rendahnya harga perdana saham yang akan dibeli investor tergantung kesepakatan antara emiten dengan underwriter, walaupun emiten dan underwriter bersama-sama dalam penentuan harga perdana saham, namun sebenarnya masing-masing pihak mempunyai kepentingan yang berbeda. Reputasi underwriter menjadi menjadi tolok ukur bagi para investor untuk mendapatkan informasi yang relevan dan dapat dipercaya sebagai pertimbangan investasi.

Fakta fenomena underpricing lebih banyak terjadi pada perusahaan yang melakukan penawaran umum perdana. Meskipun perusahaan telah menggunakan lembaga penjamin dan profesi penunjang yang bereputasi tinggi untuk menilai prospektus yang disediakan oleh perusahaan, hal ini tidak menjamin bahwa underpricing akan turun. Underpricing dapat dikurangi dengan cara menyajikan informasi akuntansi dan informasi non akuntansi dalam prospectus. Informasi akuntansi adalah laporan keuangan yang terdiri atas neraca, perhitungan laba/rugi, laporan arus kas dan penjelasan laporan keuangan. Informasi non akuntansi adalah informasi selain laporan keuangan, salah satu informasi non akuntansi yang perlu disajikan adalah intelektual capital (Lang dan Russel 2000).

Meskipun studi tentang underpricing telah banyak dilakukan, namun penelitian ini masih menarik karena tingginya tingkat underpricing, yang secara teori seharusnya tingkat underpricing dapat diminimalisir dengan research gap antar peneliti disamping itu beberapa penelitian hasilnya tidak konsiten. Berdasarkan permasalahn tersebut, maka penelitian ini akan menguji kembali pengaruh Intellectual Capital Disclosure dan Underwriter Reputation terhadap IPO Underpricing. Penelitian dilakukan pada perusahaan yang terdaftar di Bursa Efek Indonesia untuk periode 2007 sampe 2012.

\section{Landasan Teori dan Hipotesis}

\subsection{Signaling Theory}

Informasi merupakan unsur penting bagi investor dan pelaku bisnis karena informasi pada hakekatnya menyajikan keterangan, catatan atau gambaran baik untuk keadaan masa lalu, saat ini maupun keadaan masa yang akan datang bagi kelangsungan suatu perusahaan dan bagaimana efek pasarnya. Informasi yang lengkap, relevan, akurat dan tepat waktu sangat diperlukan oleh investor di pasar modal sebagai alat analisis untuk pengambilan keputusan investasi.

Teori ini didasarkan pada premis bahwa manajer dan pemegang saham tidak mempunyai akses informasi perusahaan yang sama. Ada informasi tertentu yang hanya diketahui oleh manajer, sedangkan pemegang saham tidak tahu informasi tersebut. Jadi, ada informasi yang tidak simetri (asymmetric information) antara manajer dan pemegang saham. Akibatnya, ketika struktur modal ataupun kondisi perusahaan mengalami perubahan, hal itu dapat membawa informasi kepada pemegang saham yang akan mengakibatkan nilai perusahaan berubah. Dengan kata lain, terjadi pertanda atau sinyal (signalling).

Signalling teory menjelaskan bagaimana seharusnya sinyal-sinyal keberhasilan atau kegagalan manajemen (perusahaan) disampaikan kepada pemilik (investor). Berdasarkan teori ini perusahaan dituntut memberikan pengungkapan penuh kondisinya agar investor dapat memperoleh informasi yang mendorong keputusan investasi mereka. Informasi merupakan unsur penting bagi investor dan pelaku bisnis karena informasi yang lengkap, akurat dan tepat waktu bermanfaat sebagai alat analisis untuk mengambil keputusan investasi. Apabila pengumuman tersebut mengandung nilai positif, maka diharapkan pasar akan bereaksi pada waktu pengumuman tersebut diterima oleh pasar. 
Reaksi pasar ditunjukkan dengan adanya perubahan harga saham pada waktu informasi diumumkan dan semua pelaku pasar sudah menerima informasi tersebut, dimana pelaku pasar terlebih dahulu menginterpretasikan dan menganalisis informasi tersebut sebagai sinyal baik (good news) atau sinyal buruk (bad news). Jika pengumuman informasi tersebut sebagai sinyal baik bagi investor, maka terjadi perubahan dalam harga saham, dimana harga saham menjadi naik dan sebaliknya. Dengan demikian informasi akuntansi maupun non akuntansi dapat mempengaruhi ekspektasi investor terhadap intial return setelah IPO.

Teori ini yang paling memungkinkan untuk menjelaskan fenomena IPO underpricing secara komprehensif. Dalam teori ini, diasumsikan bahwa emiten memiliki informasi yang sempurna tentang nilai perusahaan dan investor adalah entitas uninformed. Investor kemudian menilai perusahaan sebagai fungsi dari mekanisme signaling yang berbeda-beda. Dalam sebuah penelitian oleh Leland dan Pyle pada 1977, kesimpulan yang didapatkan adalah bahwa perusahaan dapat memberikan sinyal nilai perusahaan kepada pihak luar dengan menahan beberapa sahamnya (Karlis 2000).

Hipotesis ini menegaskan bahwa perusahaan dengan sengaja menurunkan nilai penerbitannya yang memiliki tujuan spesifik untuk mendapatkan perhatian dari kenaikan harga saham pada hari pertama saat listing. Hal tersebut memberikan publikasi tambahan dan eksposur media bagi perusahaan dengan menyediakan nilai perusahaan kepada investor. Teknik ini dianggap sebagai grandstanding IPO dan biasanya akan dilakukan oleh perusahaan yang lebih kecil dan belum lama berdiri yang membutuhkan perhatian investor dan yang nilainya dianggap sangat tidak pasti oleh investor potensial. Oleh karena itu, tingkat undepricing akan berbanding terbalik dengan ukuran atau nilai perusahaan emiten.

Willenborg (dalam Karlis 2000) menemukan bahwa meskipun semua perusahaan mendapatkan keuntungan dari reputasi auditor, perusahaan yang memiliki ukuran berbedabeda memilki alasan yang berbeda-beda juga dalam memilih underwriter dan auditor yang presitisius. Jika sebuah perusahaan menggunakan jasa auditor yang memiliki reputasi baik, sinyal yang diberikan kepada investor adalah bahwa perusahaan akan mendapatkan keuntungan dengan hasil analisis laporan keuangan yang lebih akurat (proses audit oleh auditor). Menurut Karlis 2000, teori ini juga mengasumsikan bahwa underwriter mengetahui efek signaling dan menggunakannya saat menyetujui kontrak IPO.

Untuk menurunkan risiko penurunan (overpricing), underwriter akan menurunkan harga saham perdana pada saat IPO. Dengan melakukan hal demikian, mereka menurunkan risiko yang dapat merusak reputasi mereka dengan penawaran yang undersubscribed dan overpriced, atau menyeret mereka dalam proses pengadilan efek yang melibatkan investor dalam emiten yang memiliki risiko tinggi. Ketidakpastian perusahaan dalam melakukan emisi saham dan motif perusahaan untuk menjaga dan meningkatkan kredibilitas perusahaan adalah katalis-katalis di balik tujuan underwriter untuk menurunkan harga penawaran saham perdana.

Determinan yang paling penting dalam ketidakpastian adalah nilai pasar emiten yang disetujui dan ukuran perusahaan emiten. Oleh karena itu, teori ini memprediksi bahwa jika nilai pasar emiten berkurang, maka tingkat underpricing akan meningkat. Karena, di dalam banyak kasus, nilai nilai pasar emiten berhubungan secara langsung dengan nilai dan ukuran perusahaan penerbit, teori ini memenuhi tren yang sebelumnya disebutkan tentang underpricing pada masa sekarang. Dalam teori ini juga disebutkan bahwa jika ukuran dan reputasi underwriter semakin besar, maka underwriter akan cenderung untuk menurunkan nilai penerbitan. 


\subsection{Asimetri Informasi}

Asimetri informasi adalah kondisi di mana ada ketidakseimbangan perolehan informasi antara pihak manajemen sebagai penyedia informasi dengan pihak pemegang saham dan stakeholder pada umumnya sebagai pengguna informasi. Asimetri informasi terjadi karena sifat dasar manusia pada umumnya mementingkan diri sendiri, manusia memiliki daya pikir terbatas mengenai persepsi masa mendatang dan manusia selalu menghindari risiko. Berdasarkan asumsi sifat dasar manusia tersebut, menyebabkan informasi yang dihasilkan manusia untuk manusia lain selalu dipertanyakan reliabilitasnya dan dapat dipercaya tidaknya informasi yang disampaikan. Emiten, underwriter (penjamin emisi), masyarakat pemodal adalah pihak-pihak yang terlibat dalam penawaran perdana pada saat terjadinya underpricing karena adanya asimetri informasi yang menjelaskan perbedaan informasi. Model Baron (1982), menganggap underwriter memiliki informasi lebih mengenai pasar modal, sedangkan emiten tidak memiliki informasi mengenai pasar modal. Oleh karena itu, underwriter memanfaatkan informasi yang dimiliki untuk membuat kesepakatan harga IPO yang maksimal, yaitu harga yang memperkecil risikonya apabila saham tidak terjual semua. Karena emiten kurang memiliki informasi, maka emiten menerima harga yang murah bagi penawaran sahamnya. Semakin besar ketidakpastian emiten tentang kewajaran harga sahamnya, maka lebih besar permintaan terhadap jasa underwriter dalam menetapkan harga. Sehingga underwriter menawarkan harga perdana sahamnya dibawah harga ekuilibrium. Oleh karena itu akan menyebabkan tingkat underpricing semakin tinggi (Murni 2004).

\subsection{Underpricing}

Underpricing adalah suatu keadaan dimana harga saham yang diperdagangkan di pasar perdana lebih murah dibandingkan ketika diperdagangkan di pasar skunder dan memungkinkan investor memperoleh initial return positif. Fenomena underpricing inilah yang menarik investor untuk membeli saham perusahaan yang menjanjikan keuntungan bila dijual di pasar skunder. Fenomena underpricing terjadi karena adanya asimetri informasi sebagai akibat tidak seimbangnya informasi antara underwriter dengan emiten.

Harga saham yang terjadi di pasar skunder ditentukan oleh mekanisme kekuatan penawaran dan permintaan. Sedangkan harga saham yang dijual di pasar perdana (IPO) telah ditentukan lebih dahulu berdasarkan kesepakatan antara emiten dan penjamin emisi. Perbedaan penentuan harga ini terjadi karena masing-masing pihak mempunyai kepentingan yang berbeda. Emiten menginginkan dana yang banyak sesuai kesepakatan harga yang telah ditentukan, sementara underwriter berusaha menjual di pasar perdana dengan harga lebih murah untuk menarik investor, hal ini dilakukan untuk memperkecil risiko karena saham tidak laku dijual.

Emiten akan menerima harga yang murah bagi penawaran sahamnya karena kurang memiliki informasi tentang investor. Implikasinya semakin sedikitnya informasi yang dimiliki emiten dan semakin besar ketidakpastian emiten tentang kewajaran harga saham untuk investor, maka lebih besar permintaan jasa underwriter dalam menetapkan harga. Sebagai kompensasi atas informasi yang diberikan oleh underwriter, emiten mengijinkan underwriter menawarkan harga sahamnya dibawah harga ekuilibrium. Dengan demikian semakin besar ketidakpastian akan semakin besar risiko yang dihadapi underwriter, maka tingkat underpricing semakin tinggi.

Underpricing merupakan biaya tidak langsung bagi perusahaan yang melakukan IPO. Artinya, bila harga saham dapat diterima di pasar dengan harga yang lebih tinggi, kenapa tidak dijual dengan harga tersebut, yaitu harga pada saat penutupan hari pertama dipasar sekunder. Para pemilik perusahaan menginginkan agar dapat meminimalisir underpricing 
karena terjadinya underpricing akan menyebabkan transfer kemakmuran dari pemilik kepada investor (Beatty 1989).

Mc Donald dan Fisher (1973) dalam Nyoman dan Suad (2004:426) menyatakan bahwa pada saat terjadinya underpricing, perbedaan antara offering price dengan harga pasar setelah penawaran perdana merupakan "rent" atau bayaran yang didistribusikan oleh penjamin emisi kepada pembeli awal saham, sehingga IPO akan meningkat dengan tajam setelah diperdagangkan di pasar sekunder.

Investor tidak akan membeli saham jika informasi yang didapat tidak cukup meyakinkan untuk mendapatkan keuntungan pada pembelian saham perdana. Sedangkan biaya penyebaran informasi perusahaan yang sempurna pada calon pembeli tidak murah, sehingga untuk mengkompensasikan informasi yang kurang tersebut perusahaan melakukan underpricing. Semakin tinggi ketidakpastian semakin tinggi pula tingkat underpricing yang ditanggung perusahaan.

\subsection{Pengungkapan Intelektual Capital}

Intelektual capital adalah intelektual yang diformalkan, ditangkap, dan dimanfaatkan untuk menghasilkan asset senilai lebih tinggi (Guthrie dan Richard 2000). Menurut Bontis (2001) saat ini belum ada standar akuntansi yang mengatur secara sistematis tentang pengidentifikasian, pengukuran, dan pelaporan intelektual capital sehingga pengungkapan masih bersifat sukarela. Intellectual capital disclosure akan meningkatkan relevansi dan reliabilitas laporan keuangan terutama untuk memprediksi kinerja keuangan perusahaan dimasa yang akan datang. Intellectual capital sering didefinisikan sebagai sumber daya pengetahuan dalam bentuk karyawan, pelanggan, proses atau teknologi yang dapat digunakan perusahaan dalam proses penciptaan nilai bagi perusahaan (Bukh et al. 2005).

Singh dan Van der Zahn $(2007 ; 2008)$ dalam penelitiannya menggunakan indeks pengungkapan intellectual capital yang dikembangkan dari indeks penelitian sebelumnya oleh Bukh et al. (2005). Indeks pengungkapan tersebut dari 84 item yang membagi intellectual capital menjadi 6 komponen, yaitu: karyawan ada 28 item, pelanggan ada 16 item, teknologi informasi ada 6 item, proses ada 9 item, riset dan pengembangan (R\&D) ada 9 item, serta pernyataan strategis ada 16 item.

\subsection{Reputasi Underwriter}

Penjamin emisi efek adalah pihak yang membuat kontrak dengan emiten untuk melakukan penawaran umum bagi kepentingan emiten dengan atau tanpa kewajiban membeli sisa efek yang tidak terjual (Jogiyanto 2010). Sedangkan menurut Tandelilin (2011) penjamin emisi berperan sebagai lembaga perantara emisi yang menjamin penjualan sekuritas yang diterbitkan emiten. Penjamin emisi merupakan mediator yang mempertemukan emiten dan investor.

Underwriter harus membuat strategi untuk mengalokasikan saham kepada investor dan harus dapat memberikan informasi berharga mengenai harga IPO. Adanya hubungan antara investor (investor institusi) dengan underwriter dimasa lalu, memungkinkan underwriter mengalokasikan saham lebih besar untuk investor yang sama dalam industri yang sama. Pengalokasian saham yang besar kepada investor institusi, akan mempengaruhi besarnya underpricing karena adanya kepentingan underwriter dalam menyukseskan penjualan saham perdana yang dijaminnya serta kontrol yang dimiliki oleh investor institusi dalam mempengaruhi level aktivitas IPO dan dalam membentuk level underpricing.

\subsection{Modal Intelektual dan Underpricing}


Berdasarkan teori signaling, emiten dan underwriter biasanya dengan sengaja akan menurunkan harga penawaran saham perdana dengan tujuan untuk mengkompensasi investor atas adanya informasi asimetri yang terjadi. Teori ini juga menjelaskan bagaimana informasi asimetri dapat dikurangi dengan cara salah satu pihak memberikan signal informasi kepada pihak lain. Agar sinyal tersebut efektif, maka harus dapat ditangkap pasar dan dipersepsikan baik, serta tidak mudah ditiru oleh perusahaan yang berkualitas buruk. Salah satu informasi yang dapat dijadikan sinyal adalah pengumuman yang dilakukan oleh emiten. Peningkatan pengungkapan informasi keuangan dan non-keuangan dalam prospectus dianggap sebagai mekanisme potensial untuk mengurangi asimetri informasi yang terjadi pada saat IPO (Bukh 2003).

Pengungkapan intelektual capital menjadi salah satu komponen penting dalam pengungkapan di dalam prospectus. Dengan adanya pengungkapan intelektual capital, diharapkan dapat mengurangi terjadinya informasi asimetri sehingga investor dapat menerima sinyal positif dengan memperoleh lebih banyak informasi mengenai perusahaan dan menilai perusahaan dengan lebih baik. Ketidakpastian yang dapat mempengaruhi tingkat underpricing dapat berkurang dan underpricing akan lebih rendah. Dari paparan tersebut, maka hipotesis yang diajukan dalam penelitian ini adalah:

\section{H1: Pengungkapan intelektual capital berpengaruh negatif terhadap tingkat underpricing}

\subsection{Reputasi Underwriter dan Underpricing}

Semakin besar ketidakpastian akan semakin besar risiko yang dihadapi underwriter, maka akan menyebabkan tingkat underpricing semakin tinggi. Hal ini disebabkan karena underwriter menggunakan kesanggupan penuh (full commitment underwriting) sehingga underwriter mengikatkan diri untuk menawarkan saham kepada publik dan membeli sisa saham. Keadaan ini membuat underwriter berusaha menjual di pasar perdana kemudian membeli saham yang tidak laku dengan harga sama dengan penawaran di pasar perdana. Agar saham habis terjual, maka underwriter berusaha menekan harga.

Reputasi penjamin emisi dapat digunakan sebagai sinyal untuk mengurangi tingkat ketidakpastian yang tidak dapat diungkapkan oleh informasi yang terdapat dalam prospectus dan memberi sinyal bahwa informasi privat dari emiten mengenai prospek perusahaan di masa yang akan datang. Pasar percaya bahwa underwriter yang bereputasi baik tidak akan menjamin perusahaan yang berkualitas rendah. Sehingga semakin tinggi reputasi underwriter maka mencerminkan risiko perusahaan IPO tersebut rendah serta rendah pula tingkat ketidakpastian harga saham di masa yang akan datang, sehingga tingkat underpricing juga rendah (Carter dan Steven 1990). Dari paparan tersebut, maka hipotesis yang diajukan dalam penelitian ini adalah:

\section{H2: Reputasi underwriter berpengaruh negatif terhadap IPO underpricing}

\section{Metoda Penelitian}

Metode pemilihan sampel yang digunakan dalam penelitian ini adalah purposive sampling, yaitu seluruh perusahaan yang melakukan IPO dan mengalami underpricing di Bursa Efek Indonesia periode Januari 2007- Desember 2012. Data yang diperlukan meliputi data kuantitatif berupa data harga penawaran saham perdana (offering price) saham, harga penutupan (closing price) saham hari pertama di pasar skunder. Data kualitatif yang diperlukan berupa data pengungkapan intelektual capital dan underwriter. Data tersebut diperoleh dari www.idx.co.id, IDX Fact book, IDX Statistic 2007 - 2012, ICMD 2007 - 
2012, PDEB UGM, Media masa, internet serta publikasi lain yang dapat membantu penelitian ini.

Berikut jumlah sampel yang digunakan dalam penelitian ini:

Tabel 1 Sampel penelitian

\begin{tabular}{lc}
\hline \hline Keterangan & Jumlah \\
\hline Perusahaan yang melakukan IPO periode 2007 - 2012 & 125 \\
Perusahaan yang tidak underpricing & $(22)$ \\
Perusahaan yang laporannya keuangannya negatif & $(3)$ \\
Sampel yang digunakan & 100 \\
\hline \hline
\end{tabular}

Untuk menjawab hipotesis digunakan model sebagai berikut:

$\mathrm{UND}_{\mathrm{i}}=\alpha+\beta_{1} \mathrm{IC}_{\mathrm{i}}+\beta_{2} \mathrm{UR}_{\mathrm{i}}+\beta_{3} \mathrm{SIZE}_{\mathrm{i}}+\varepsilon$

\begin{tabular}{|c|c|}
\hline$\alpha$ & $=$ Konstan \\
\hline$\beta$ & $=$ Koefisien regresi \\
\hline$\varepsilon$ & $=$ residual error \\
\hline $\mathrm{UND}_{\mathrm{i}}$ & $=$ Tingkat underpricing perusahaan ${ }_{\mathrm{i}}$ \\
\hline $\mathrm{IC}_{\mathrm{i}}$ & $=$ Modal Intellectual perusahaan $_{\mathrm{i}}$ \\
\hline $\mathrm{RU}_{\mathrm{i}}$ & $=$ Reputasi Underwriter perusahaan \\
\hline SIZE $_{i}$ & $=$ Ukuran perusahaan $_{\mathrm{i}}$ \\
\hline
\end{tabular}

Tingkat underpricing perusahaan (notasi UND)

Underpricing diukur dengan menggunakan initial return atau return awal yaitu selisih antara harga saham pada hari pertama penutupan (closing price) pada pasar skunder dikurangi harga di pasar perdana dibagi dengan harga di pasar perdana

$$
\begin{gathered}
\text { closing price }- \text { offering prices } \\
\text { Initial Return }=\text { offering prices }
\end{gathered}
$$

Intellectual Capital (notasi IC)

Pengungkapan intelektual capital digunakan indek untuk menentukan persentase pengungkapan dalam prospectus dengan content analysis. Content analysis dilakukan dengan membaca laporan prospectus atau annual report setiap perusahaan sampel dan memberi kode dikotomi tanpa mempertimbangkan bobot masing-masing yaitu memberi skor 1 jika atribut intelektual capital diungkapkan, dan skor 0 jika atribut intelektual capital tidak diungkapkan. Selanjutnya, indeks pengungkapan dihitung dengan cara berikut;

$$
\begin{gathered}
\text { Jumlah IC yang diungkapkan dalam prospectus } \\
\text { Indek intelektual capital }=\text {------- } 100 \% \text { Jumlah IC yang seharusnya diungkapkan }
\end{gathered}
$$


Jumlah pengungkapan intelektual capital yang seharusnya dalam penelitian ini ada 84 item yang digunakan oleh Singh dan Van der Zahn (2007) dengan menggunakan indeks pengungkapan intellectual capital yang dikembangkan dari indeks penelitian sebelumnya oleh Bukh et al. (2005). Indeks pengungkapan tersebut dari 84 item yang membagi intellectual capital menjadi 6 komponen, yaitu: karyawan ada 28 item, pelanggan ada 16 item, teknologi informasi ada 6 item, proses ada 9 item, riset dan pengembangan (R\&D) ada 9 item, serta pernyataan strategis ada 16 item.

\section{Reputasi Underwriter (notasi RU)}

Reputasi underwriter diukur dengan memberi kode 1 untuk penjamin emisi yang masuk peringkat 20 dari 50 most active IDX members in total trading frequency dan kode 0 untuk penjamin emisi yang tidak masuk peringkat 20 dari 50 most active IDX members in total trading frequency.

Ukuran perusahaan (sebagai variabel control = notasi size)

Ukuran perusahaan diukur dengan menggunakan logaritma natural (ln) dari total asset yang dimiliki perusahaan pada periode terakhir sebelum melakukan IPO. Menurut Martani dan Chastina 2005, perusahaan dengan asset besar akan memberikan sinyal bahwa perusahaan memiliki prospek bagus dan dapat mengurangi ketidakpastian dimasa yang akan datang. Hal ini mengindikasikan bahwa ada hubungan antara ukuran perusahaan dengan tingkat underpricing.

\section{Hasil dan Pembahasan}

Tabel 2 Deskripsi data

\begin{tabular}{llllcl}
\hline \hline Variabel & $\mathrm{N}$ & Minimum & Maksimum & Mean & Deviasi Std. \\
\hline IPO Underpricing & 100 & 0,014 & 0,710 & 0,297 & 0.211 \\
IC Disclosure & 100 & .071 & 0,675 & 0,341 & 0.157 \\
Size & 100 & 18,718 & 31,519 & 27.644 & 2.078 \\
\hline \hline
\end{tabular}

Tabel 2 menunjukkan bahwa rata-rata underpricing saham dari pengamatan terhadap 100 perusahaan lebih dari $25 \%$, rata-rata pengungkapan modal intelektual pada perusahaan kurang dari 50\%. Emiten yang mengalami underpricing terendah 1,4\% adalah PT Elang Mahkota Teknologi Tbk, sedangkan emiten dengan tingkat underpricing tertinggi adalah $71 \%$ terjadi pada perusahaan Bekasi Asri Pemula Tbk, Triwira Insanlestari Tbk, Destinasi Tirta Nusantara Tbk, PT Bank Sinarmas Tbk, dan PT Multifiling Mitra Indonesia Tbk, Tri Bayan Tirta Tbk, dan Waskita Karya Tbk. Pengungkapan modal intelektual terendah 7,1\% oleh PT Golden Retalindo Tbk dan pengungkapan modal intelektual tertinggi 67,5\% PT Indofood CBP Sukses Makmur Tbk.

Tabel 3 Deskripsi data berdasar kelompok pengungkapan

\begin{tabular}{lcccc}
\hline \hline Keterangan & Sampai 50\% & \multicolumn{3}{c}{ Lebih dari 50\% } \\
\hline & Jumlah sampel & Rata-rata & Jumlah sampel & Rata-rata \\
IPO Underpricing & 84 & $19,22 \%$ & 16 & $65,19 \%$ \\
IC Disclosure & 86 & $29,59 \%$ & 14 & $61,79 \%$ \\
\hline \hline
\end{tabular}




\begin{tabular}{lcc}
\hline \hline & IC Disclosure Sampai & IC Disclosure lebih dari \\
& $50 \%$ & $50 \%$ \\
\hline \hline IPO Underpricing & $29,5 \%$ & $27,45 \%$ \\
\hline \hline
\end{tabular}

Pada tabel 3 terlihat bahwa dari 100 sampel perusahaan yang diamati dengan tingkat underpricing kurang dari 50\% lebih banyak daripada perusahaan yang mengalami underpricing lebih dari 50\%. Perusahaan dengan tingkat pengungkapan intellectual capital kurang dari 50\% juga lebih banyak dari perusahaan dengan tingkat pengungkapan intellectual capital lebih dari 50\%. Perusahaan yang mengungkapkan intelektual capital sampai 50\% mengalami underpricing lebih besar dari perusahaan yang mengungkapkan intellectual capital lebih dari 50\%. Hal ini menunjukkan bahwa semakin tinggi tingkat pengungkapan intellectual capital akan semakin rendah tingkat underpricing saham.

Tabel 4: Deskripsi data untuk reputasi underwriter

\begin{tabular}{lcc}
\hline \hline Keterangan & Frekuensi & Persen \\
\hline \hline Tidak masuk peringkat & 42 & 42 \\
Masuk Peringkat & 58 & 58 \\
Total & 100 & 100 \\
\hline \hline
\end{tabular}

Pada tabel 4 tersebut terlihat bahwa penjamin emisi yang masuk peringkat 20 dari 50 most active IDX members in total trading frequency lebih dari 50\%. Hal ini mengindikasikan bahwa lebih dari $50 \%$ penjamin emisi dalam perusahaan sampel adalah penjamin emisi yang berkualitas termasuk dalam peringkat 20 dari 50 most active IDX members in total trading frequency.

Hasil Analisis Regresi untuk menguji hipotesis dapat dilihat pada tabel 5 berikut:

Tabel 5 Hasil uji hipotesis

\begin{tabular}{lclll}
\hline \hline & Koefisien & $\mathrm{T}$ & Sig & VIF \\
\hline Constant & 0.474 & 1.783 & 0.078 & \\
Modal Intelektual & -0.292 & $-2.163^{*}$ & 0.033 & 1.040 \\
Reputasi Underwriter & -0.144 & $-3.561^{*}$ & 0.001 & 1.017 \\
Ukuran Perusahaan & 0.00 & 0.023 & 0.982 & 1.047 \\
\hline ependen Variabel: Underpricing & Durbin-Watson; 1.805 \\
F Statistik: 6.341 & & Signifikansi: 0,001 \\
$\mathrm{R}^{2}: 0,165$ & & Adjusted $\mathrm{R}^{2}: 0,139$ & \\
\hline
\end{tabular}

$\overline{{ }^{*} \text { signifikan pada } \alpha=5 \%, \mathrm{R}^{2} \text { dan Adjusted } \mathrm{R}^{2} \text { untuk menguji besarnya }}$ korelasi, F Statistik untuk menguji model

Pada tabel 5 dapat dilihat hasil uji asumsi klasik gejala multikolonearitas data dengan VIF (Variance Inflation Factor) kurang dari 10 menunjukkan bahwa model regresi terbebas dari gangguan multikolinearitas (Ghozali 2007). Hasil uji autokolerasi menujukkan nilai DurbinWatson berada diantara nilai du -4 du atau antara 1,6819-2,3181 berarti tidak terjadi gejala autokorelasi dalam model regresi. Nilai koefisien determinasi $\left(\mathrm{R}^{2}\right)$ sebesar $16,5 \%$ dan adjusted $\mathrm{R}^{2}$ sebesar $13,9 \%$. Hal ini menunjukkan bahwa variabel modal intelektual dan 
reputasi underwriter hanya dapat menjelaskan 16,5\% (13,9\%), sehingga masih banyak variabel yang bisa diteliti berkaitan dengan underpricing saham saat IPO.

Hasil regresi berganda menunjukkan nilai $\mathrm{F}$ statistik kurang dari 5\%, hal ini menunjukkan bahwa model dalam penelitian ini dapat digunakan. Hasil uji hipotesis pada tabel 5 terlihat bahwa nilai signifikansi untuk variabel intellectual capital disclosure dan reputasi underwriter signifikan dibawah 5\% dengan angka t negative. Hal ini menunjukkan bahwa intellectual capital disclosure dan reputasi underwriter secara negative mempengaruhi tingkat underpricing. Hal ini menunjukkan bahwa semakin tinggi intellectual capital disclosure, maka dapat mengurangi underpricing, begitu juga reputasi underwriter yang baik dapat mengurangi underpricing.

Intellectual capital disclosure dapat mengurangi asimetri informasi antara investor dengan agen perusahaan yang dapat mempengaruhi tingkat underpricing. Intellectual capital disclosure dapat menjadi salah satu sumber informasi yang bermanfaat bagi pihak-pihak yang berkepentingan terhadap perusahaan dalam proses pembuatan keputusan, karena intellectual capital disclosure dapat membuat laporan keuangan menjadi lebih relevan dan reliabel terutama untuk memprediksi kinerja keuangan di masa yang akan datang. Hal ini menunjukkan bahwa investor mulai mempertimbangkan intellectual capital disclosure sebagai salah satu hal yang diperhatikan untuk pengambilan keputusan dalam membeli saham perdana.

Reputasi underwriter merupakan sinyal bagi pasar. Underwriter dengan reputasi yang baik akan memberikan sinyal positif terhadap pasar karena underwriter dengan reputasi yang baik memiliki banyak informasi di pasar modal dan lebih memiliki kemampuan dalam mengelola harga saham. Dengan adanya sinyal positif yang diberikan oleh underwriter dengan reputasi yang baik, maka tingkat underpricing dapat dikurangi.

\section{Simpulan}

Pengujian menggunakan analisis regresi memperoleh hasil bahwa intellectual capital disclosure dan reputasi underwriter berpengaruh negative terhadap underpricing saham. Hal ini mengindikasikan bahwa intellectual capital disclosure yang tinggi dan reputasi underwriter yang baik dapat mengurangi underpricing saham saat IPO di Bursa Efek Indonesia. Hasil pengujian koefisien determinasi dalam penelitian ini masih rendah sehingga perlu menguji dengan menambah variabel lain seperti leverage, ROE, kondisi perekonomian, struktur kepemilikan, rata-rata kurs, jenis industry, karakteristik investor dan reputasi auditor. Penelitian selanjutnya juga dapat menguji intellectual capital disclosure dengan cara memisahkan pengungkapan yang wajib (mandatory) dengan pengungkapan yang sukarela (voluntary). 


\section{Daftar Referensi}

Baron. 1982. A Model of the Demand for Investment Banking Advising and Distribution Services for New Issues. Journal of finance 37/4: 955-976.

Beatty, Randolph P. 1989. Auditor Reputation and the Pricing of Initial Public Offerings. The Accounting Review. Vol 64/4: 693-709.

Bontis, Nick. 2001. Assessing Knowledge Assets: A Review of the Models Used to Measure Intellectual Capital. International Journal of Management Reviews. Vol. 3/1: 41-60.

Bukh, Per Nikolaj. 2003. The Relevance of Intellectual Capital Disclosure: A Paradox?. Accounting, Auditing, and Accountability Journal. Vol. 16/1: 49-56.

Bukh, Per Nikolaj. Christian Nielsen. Peter Gormsen. dan Jan Mouritsen. 2005. Disclosure of Information on Intellectual Capital in Danish IPO Prospectuses. Accounting, Auditing, and Accountability Journal. Vol. 18/6: 713-732.

Carter, Richard dan Steven Manaster. 1990. Initial Public Offerings and Underwriter Reputation. The Journal of Finance. Vol. 45/4: 1045- 1067.

Ghozali, Imam. 2007. Aplikasi Analisis Multivariate dengan Program SPSS. Semarang: Badan Penerbit Universitas Diponegoro.

Guthrie, James dan Richard Petty. 2000. Intellectual Capital Literature Review; Measurement, reporting, and Management. Journal of Intellectual Capital, Vol 1, No. 2: $156-176$

Jogiyanto, Hartono. 2010. Teori Portofolio dan Analisis Investasi. Edisi Ketujuh. Yogyakarta: BPFE

Karlis, Peter L. 2000. IPO Underpricing. The Park Place Economist. Vol. 8: 81-89.

Lang, Mark H. dan Russel J. Lundholm. 2000. Voluntary Disclosure and Equity Offerings: Reducing Information Asymmetry or Hyping the Stock?. Contemporary Accounting Research. Vol. 17/4: 623-662.

Martani, Dwi dan Yolana, Chastina. 2005. Variabel-variabel yang Mempengaruhi Fenomena Underpricing Pada Penawaran Saham Perdana di BEJ Tahun 1994 2001. Proceedings. Simposium Nasional Akuntansi VIII, Solo, Indonesia: 538-553.

Murni, Siti Asiah. 2004. Pengaruh Luas Ungkapan Sukarela dan Asimetri Informasi Terhadap Cost of Equity Capital pada Perusahaan Publik di Indonesia. Jurnal Riset Akuntansi Indonesia. Vol. 7/2: 192-206.

Nyoman, T dan Suad Husnan. 2004. Perbandingan Abnormal Return Emisi Saham Perdana Perusahaan Keuangan dan Non-keuangan di Pasar Modal Indonesia: Pengujian Terhadap Hipotesis Informasi Asimetri. Sosiosains. XVII/3 
Singh, Inderpal dan Mitchell Van der Zahn. 2007. Does Intellectual Capital Disclosure Reduce an IPO's Cost of Capital? The Case of Underpricing. Journal of Intellectual Capital, Vol. 8/3: 404-516.

Singh, Inderpal dan Mitchell Van der Zahn. 2008. Determinants of Intellectual Capital Disclosure in Prospectuses of Initial Public Offerings. Journal of Accounting and Business Research. Vol. 38/5: 409-431.

Tandelilin, Eduardus. 2011. Analisis Investasi \& Manajemen Portofolio. Yogyakarta: BPFE Yogyakarta.

Trisnaningsih. 2005. Analisis Faktor-faktor yang Mempengaruhi Tingkat Underpricing pada Perusahaan yang Go Public di Bursa Efek Jakarta, Jurnal Akuntansi dan Keuangan. Vol/2: 195-210

\section{Lampiran}

Daftar Perusahaan Sampel

\begin{tabular}{|c|c|c|c|}
\hline No & CODE & Emiten & IPO Date \\
\hline 1 & BISI & Bisi Internasioanal Tbk & 28-Mei-07 \\
\hline 2 & WEHA & Panorama Transportasi Tbk & 31-Mei-07 \\
\hline 3 & BKDP & Bukit Dramo Property Tbk & 15-Jun-07 \\
\hline 4 & SGRO & Sampoerna Agro Tbk & 18-Jun-07 \\
\hline 5 & MNCN & Media Nusantara Citra Tbk & 22-Jun-07 \\
\hline 6 & MCOR & Bank Windu Kentjana Internasional Tbk & 3-Jul-07 \\
\hline 7 & PKPK & Perdana Karya Perkasa Tbk & 11-Jul-07 \\
\hline 8 & LCGP & Laguna Capital Griya Tbk & 13-Jul-07 \\
\hline 9 & DEWA & Darma Henwa Tbk & 26-Sep-07 \\
\hline 10 & BACA & Bank Capital Indonesia Tbk & 04-Okt-07 \\
\hline 11 & GPRA & Perdana Gapuraprima Tbk & $10-O k t-07$ \\
\hline 12 & WIKA & Wijaya Karya ( persero) Tbk & 9-Jul-07 \\
\hline 13 & ACES & Ace Hardware Indonesia Tbk & 6-Nov-07 \\
\hline 14 & PTSN & Sat Nusapersada Tbk & 8-Nov-07 \\
\hline 15 & JSMR & Jasa Marga( Persero) Tbk & 12-Nov-07 \\
\hline 16 & JKON & Jaya Konstruksi Manggala Pratama Tbk & 04-Des-07 \\
\hline 17 & CSAP & Catur sentosa Adiprana Tbk & 12-Des-07 \\
\hline 18 & ASRI & Alam Sutera Reality Tbk & 18-Des-07 \\
\hline 19 & ITMG & Indo Tambangraya Megah Tbk & 18-Des-07 \\
\hline 20 & COWL & Cowell Development Tbk & 19-Des-07 \\
\hline 21 & $\mathrm{ADRO}$ & Adaro Energy Tbk & 16-Jul-08 \\
\hline 21 & BAEK & Bank Ekonomi Raharja Tbk & 8-Jan-08 \\
\hline 23 & BAPA & Bekasi Asri Pemula Tbk & 14-Jan-08 \\
\hline 24 & DBSDE & Bumi Serpong Damau Tbk & 6-Jun-08 \\
\hline
\end{tabular}




\begin{tabular}{|c|c|c|c|}
\hline 25 & YPAS & Yanaprima Hastpersada Tbk & 5-Mar-08 \\
\hline 26 & ELSA & Elnusa Tbk & 6-Feb-08 \\
\hline 27 & GZCO & Gosco Plantations Tbk & 15-Mei-08 \\
\hline 28 & TPIA & Candrha Asri Putra chemical Tbk & 26-Mei-08 \\
\hline 29 & TRAM & Trada Maritime Tbk & 10-Sep-08 \\
\hline 30 & TRIL & Triwira Insanlestari Tbk & 28-Jan-08 \\
\hline 31 & KOIN & Kokoh Inti Arebama Tbk & 9-Apr-08 \\
\hline 32 & SIAP & Sekawan Inti Pratama Tbk & 17-Okt-08 \\
\hline 33 & HOME & Hotel Manadarin Regency Tbk & 17-Jul-08 \\
\hline 34 & INDY & Indika Energy Tbk & 11-Jun-08 \\
\hline 35 & PDES & Destinasi Tirta Nusantara Tbk & 8-Jul-08 \\
\hline 36 & BWPT & BW Plantation Tbk & 27-Okt-09 \\
\hline 37 & DSSA & Dian Swastatika Sentosa Tbk & 10-Des-09 \\
\hline 38 & INFC & Inovisi Invracom Tbk & 3-Jul-09 \\
\hline 39 & TRIO & Trikomsel Oke Tbk & 14-Apr-09 \\
\hline 40 & BBTN & Bank Tabungan Negeri ( persero) Tbk & 17-Des-09 \\
\hline 41 & $\mathrm{BCIP}$ & Bumi Citra Permai Tbk & 11-Des-09 \\
\hline 42 & BPFI & Batavia Prosperindo Finance Tbk & 1-Jun-09 \\
\hline 43 & MKPI & Metropolitan Kentjana Tbk & 10-Jul-09 \\
\hline 44 & EMTK & PT Elang Mahkota Tbk & 12-Jan-10 \\
\hline 45 & PTPP & PT Pembangunan Perumahan ( persero) Tbk & 9-Feb-10 \\
\hline 46 & BIPI & PT Benakat Petroleum Energy Tbk & $11-F e b-10$ \\
\hline 47 & ROTI & PT Nippon Indosari Corporindo Tbk & 28-Jun-10 \\
\hline 48 & GOLD & PT Golden Retailendo Tbk & 7-Jul-10 \\
\hline 49 & SKYB & PT Skybee Tbk & 7-Jul-10 \\
\hline 50 & BCBR & PT BPD Jawa Barat dan Banten Tbk & 8-Jul-10 \\
\hline 51 & IPOL & PT Indopoly Swakarsa Industri Tbk & 9-Jul-10 \\
\hline 52 & GREEN & PT Evergreen Invesco Tbk & 9-Jul-10 \\
\hline 53 & BUVA & PT Bukit Uluwatu Villa Tbk & 12-Jul-10 \\
\hline 54 & BRAU & PT Brau Coal Energy Tbk & 19-Agust-10 \\
\hline 55 & HRUM & PT Harum Energy Tbk & 06-Okt-10 \\
\hline 56 & ICBP & PT Indofood CBP Sukses Makmur Tbk & 07-Okt-10 \\
\hline 57 & TBIG & PT Tower Bersama Infrastructur Tbk & 25-Okt-10 \\
\hline 58 & KRAS & Krakatau Steel Tbk & 10-Nop-10 \\
\hline 59 & APLN & PT Agung Podomoro Land Tbk & 11-Nop-10 \\
\hline 60 & MIDI & PT Midi utama Indenesia Tbk & 30-Nop-10 \\
\hline 61 & BSIM & PT Bank Sinarmas Tbk & 13-Des-10 \\
\hline 62 & MFMI & PT Multi Feeling Mitra Indonesia Tbk & 29-Des-10 \\
\hline 63 & MBSS & Mitrabahtera Segara Sejati Tbk & 6-Apr-11 \\
\hline 64 & SRAJ & Sejahteraraya Anugrahjaya Tbk & 11-Apr-11 \\
\hline 65 & HDFA & HD Finance Tbk & 10-Mei-11 \\
\hline
\end{tabular}




\begin{tabular}{|c|c|c|c|}
\hline 66 & BULL & Buana Listya Tama Tbk & 23-Mei-11 \\
\hline 67 & SIMP & Salim Ifomas Pratama Tbk & 9-Jun-11 \\
\hline 68 & TIFA & Tifa Fince Tbk & 8-Jul-11 \\
\hline 69 & PTIS & Indo Straits Tbk & 12-Jul-11 \\
\hline 70 & ALDO & Alkondo Naratama Tbk & 12-Jul-11 \\
\hline 71 & STAR & Star Petrocem Tbk & 13-Jul-11 \\
\hline 72 & SUPR & Solusi Tunas Pratama & $11-\mathrm{Okt}-11$ \\
\hline 73 & ARII & Atlas Resources Tbk & 08-Nop-11 \\
\hline 74 & GEMS & Golden Energy Mines Tbk & 17-Nop-11 \\
\hline 75 & FIFA & Fisi Media Asia Tbk & 21-Apr-11 \\
\hline 76 & $\mathrm{ABMM}$ & ABM Investama Tbk & 06-Des-11 \\
\hline 77 & SDMU & Sidomulyo Selaras Tbk & 12-Jul-11 \\
\hline 78 & BAJA & Saranacentral Bajatama Tbk & 21-Des-11 \\
\hline 79 & PADI & Minna Padi Investama Tbk & 9-Jan-12 \\
\hline 80 & TELE & Tipnone Mobile Indonesia Tbk & 12-Jan-12 \\
\hline 81 & ESSA & Surya Essa Perkasa Tbk & 1-Feb-12 \\
\hline 82 & BEST & Bekasi Fajar Industrial Estate Tbk & 10-Apr-12 \\
\hline 83 & RANC & Supra Boga Lestari Tbk & 7-Jun-12 \\
\hline 84 & TRIS & Trisula Internasional Tbk & 28-Jun-12 \\
\hline 85 & KOBX & Kobexindo Tractors Tbk & 5-Jul-12 \\
\hline 86 & TOBA & Toba Bara Sejahtera Tbk & 6-Jul-12 \\
\hline 87 & MSKY & MNC Sky Vision Tbk & 9-Jul-12 \\
\hline 88 & ALTO & Tri Bayan Tirta Tbk & 10-Jul-12 \\
\hline 89 & GLOB & Global Teleshop Tbk & 10-Jul-12 \\
\hline 90 & GAMA & Gading Develop Tbk & 11-Jul-12 \\
\hline 91 & BJTM & Bank Pembangunan Daerah Jawa Timur Tbk & 12-Jul-12 \\
\hline 92 & IBST & Inti Bangun Sejahtera Tbk & 31-Aug-12 \\
\hline 93 & NIRO & Nirvana Development Tbk & 13-Sep-12 \\
\hline 94 & PALM & Provident Agro Tbk & 08-Okt-2012 \\
\hline 95 & NELY & Pelayaran Nelly Dwi Putri Tbk & 11-Okt-2012 \\
\hline 96 & TAXI & Express Transindo Utama Tbk & 2-Nov-12 \\
\hline 97 & BSSR & Baramulti Suksesarana Tbk & 8-Nov-12 \\
\hline 98 & ASSA & Adi Sarana Tbk & 12-Nov-12 \\
\hline 99 & WIIM & Wismilak Inti Makmur Tbk & 18-Nov-12 \\
\hline 100 & WSKT & Waskita Karya Tbk & 19-Nov-12 \\
\hline
\end{tabular}

